\title{
COSTUMES EM UMA FEIRA: INTERAÇÕES, VIVÊNCIAS E PERSPECTIVAS
}

\author{
Talita Vieira Aranha ${ }^{1}$ \\ Rondinell Aquino Palha ${ }^{2}$ \\ Daniel dos Santos Fernandes ${ }^{3}$
}

Mostraremos uma narrativa imagética com elementos culturais e sociais da rotina da Feira da Agricultura Familiar da Cidade de São Caetano de Odivelas. Cidade Amazônica, localizada no Nordeste Paraense, na chamada microrregião do Salgado, uma cidade ribeirinha com forte vocação para agricultura de base familiar.

Observando o comportamento dos indivíduos da respectiva feira, percebemos uma sequência de narrativas visuais que envolvem interações, vivências e perspectivas que são resultados de uma intensa e inseparável rede de relações interpessoais, que ocorrem, principalmente, em torno da comercialização dos produtos oferecidos.

Organizada pela Secretaria Municipal de Agricultura, em parceria com os agricultores familiares, a Feira da Agricultura Familiar de São Caetano de Odivelas, surgiu a partir da necessidade do fortalecimento da agricultura no município, que tinha como principal gargalo o escoamento da produção, elemento que durante muito tempo gerou uma subutilização do potencial agrícola local. Uma vez que o município é reconhecido, apenas, pela sua vocação da atividade extrativa de caranguejo, assim como da pesca artesanal.

Este cenário, aliado a ausência de infraestrutura, de logística e de um espaço adequado a comercialização dos produtos da agricultura familiar, favoreceu a evasão da produção agrícola do município para outros mercados da região circunvizinha a São Caetano de Odivelas, o que enfraquecia a visibilidade do potencial da agricultura municipal, bem como contribuía para o impedimento da movimentação econômica no mercado local. A iniciativa, da feira, fomentou a produção agrícola no município, mediante ao surgimento de novos empreendimentos de base familiar e o incremento de renda, por meio da garantia da comercialização de seus produtos.

\footnotetext{
${ }^{1}$ Engenheira de Pesca (UFRA), Discente do Programa de Pós -graduação em Desenvolvimento Rural e Gestão de Empreendimento Agroalimentares (IFPA) E-mail: talitaranhapesca@gmail.com.

${ }^{2}$ Licenciado em História (UNOPAR), Graduando em Letras- Língua Portuguesa (UFPA), Integrante do Grupo de Pesquisa Colaboratório de Interculturalidades, Inclusão de Saberes e Inovação Social (COLINS). E-mail: rondipalha@gmail.com.

${ }^{3}$ Doutor em Ciências Sociais/Antropologia. Professor Convidado no Programa de Pós-Graduação em Estudos Antrópicos na Amazônia (PPGEA) da Universidade Federal do Pará (UFPA) - Campus de Castanhal/PA, Líder do Laboratório de Estudo Linguagem, Imagem e Memórias (LELIM). Email: dasafe@ msn.com.
} 
A realidade da produção agrícola familiar do município se modificou com a criação da feira. Localidades que desenvolviam a agricultura de maneira mais tímida, passaram a ganhar destaque contribuindo com o desenvolvimento local, bem como, houve o fortalecimento de localidades que, tradicionalmente, já apresentavam sustentabilidade na produção de base familiar.

Desde o seu lançamento em dezembro de 2017, a "Feira", como carinhosamente vem sendo chamada pelos moradores e produtores, ocorre quinzenalmente na Praça dos 3 Poderes, tornando-se um espaço de interações entre seus atores sociais, pois cunhou uma ambientação para a comercialização de produtos agrícolas, além da oportunidades para outros segmentos, uma vez que a cada edição, a feira conta com apresentação de grupos culturais do município e a oferta de outros serviços como: alugueis de mesas, montagem das barracas, transporte e outros insumos; além de movimentar toda rede comercial no entorno na praça onde a "Feira" acontece.

Dentro da rotina da Feira da Agricultura Familiar de São Caetano de Odivelas, podemos observar as vivências externadas por seus participantes, como histórias de vida, de luta, de resistência, de conquistas e de desagravos, que se refletem no semblante e na postura de cada um. As vivências proporcionadas, no ambiente da "Feira", e suas diversas e variadas aprendizagens, bem como a intrínseca troca de experiências que servem como fatores motivacionais para o próprio desenvolvimento da agricultura de base familiar no município.

Freqüentada em dias fixos, a feira é um natural centro da vida social. É nela que as pessoas se encontram, conversam, se insultam, passam das ameaças às vias de fato, é nela que nascem incidentes, depois processos reveladores de cumplicidades, é nela que ocorrem aos poucos freqüentes intervenções da ronda, espetaculares, é certo, mas também prudentes, é nela que circulam as novidades políticas e as outras (BRAUDEL, 1998, p. 16).

As perspectivas de melhoramento da condição de vida dos atores sociais envolvidos no contexto da iniciativa, é percebido pela afeição criada com o momento proporcionado pela "Feira", haja vista, o comprometimento e a disponibilidade dispensada por cada um, nos dias em que a feira acontece, algo que se reflete com o fomento e o aquecimento da economia local; além da perspectiva de fortalecimento da economia rural com base nas atividades conduzidas basicamente pelo trabalho familiar independente do acesso as tecnologias ditas mais avançadas.

As imagens registradas, durante a Feira da Agricultura Familiar, busca narrar visualmente, os momentos vivenciais proporcionado neste ambiente de sociabilidades. E a 
consequente intervenção rural que quebra a rotina urbana da ribeirinha cidade de São Caetano de Odivelas.

\section{REFERÊNCIA}

BRAUDEL, Fernand. O jogo das trocas. Civilização material, economia e capitalismo: século XV-XVIII. São Paulo, Martins Fontes, 1996.

Recebido em: 15/10/2019

Aprovado em: 27/11/2019

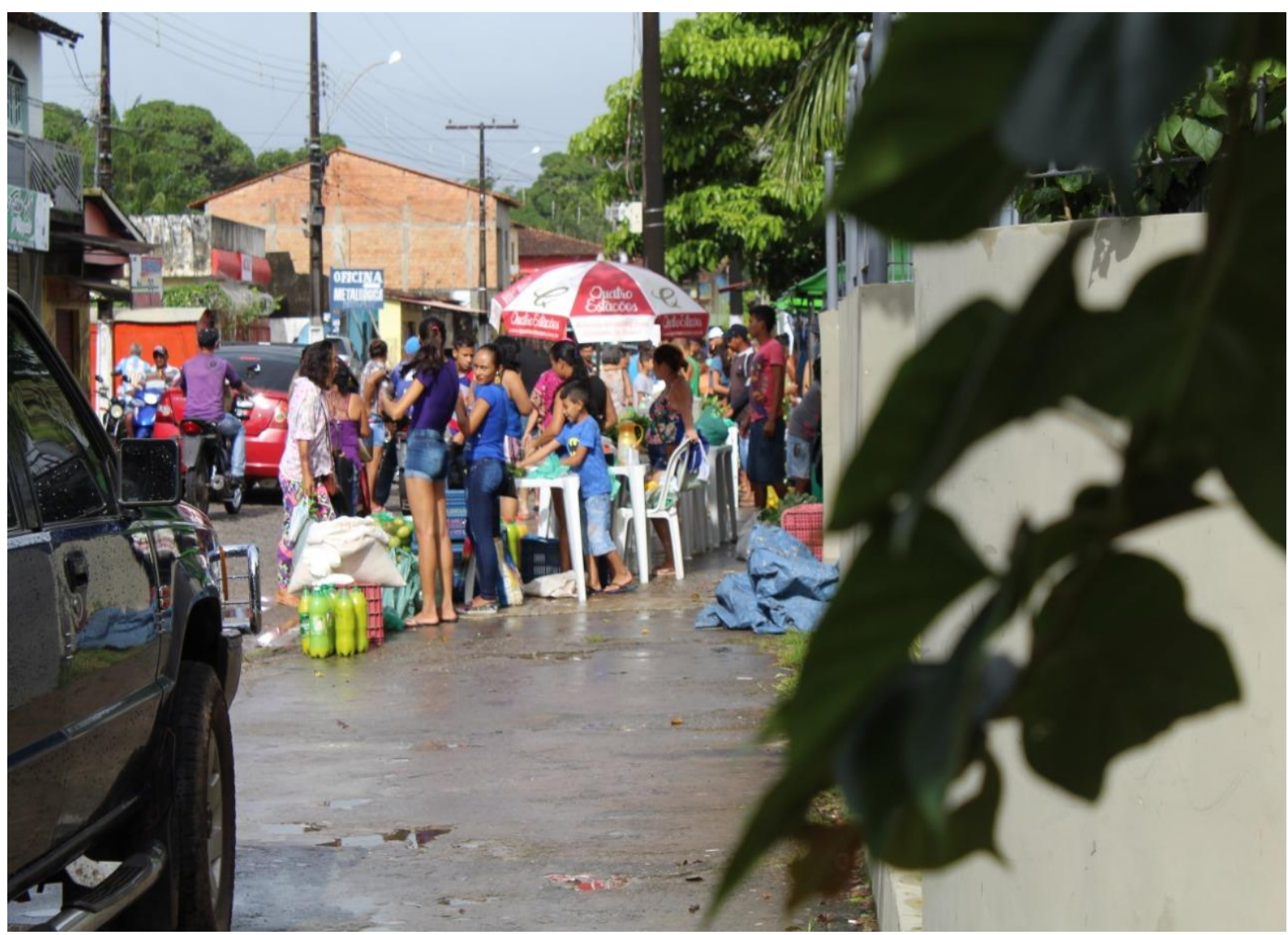



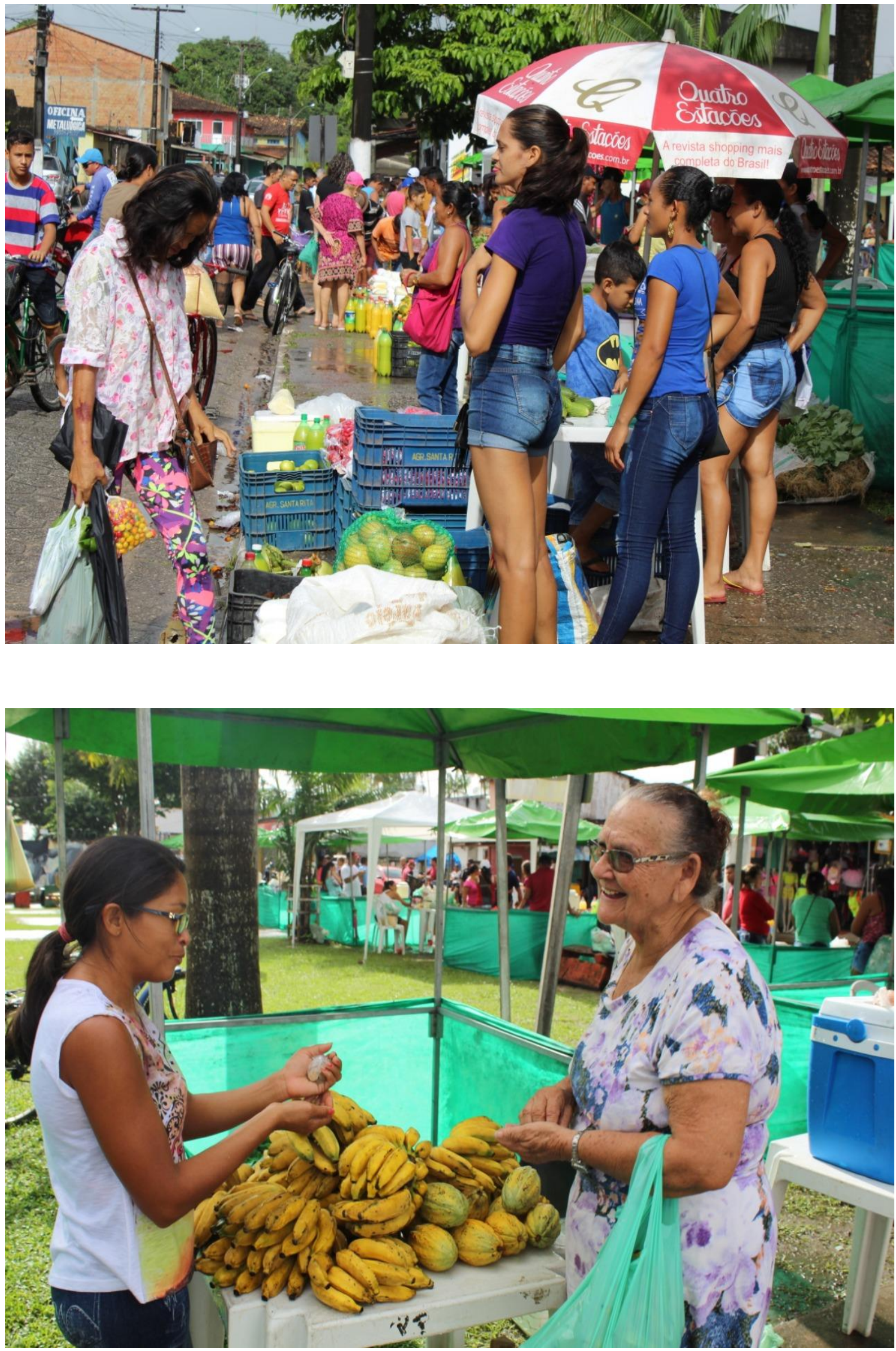

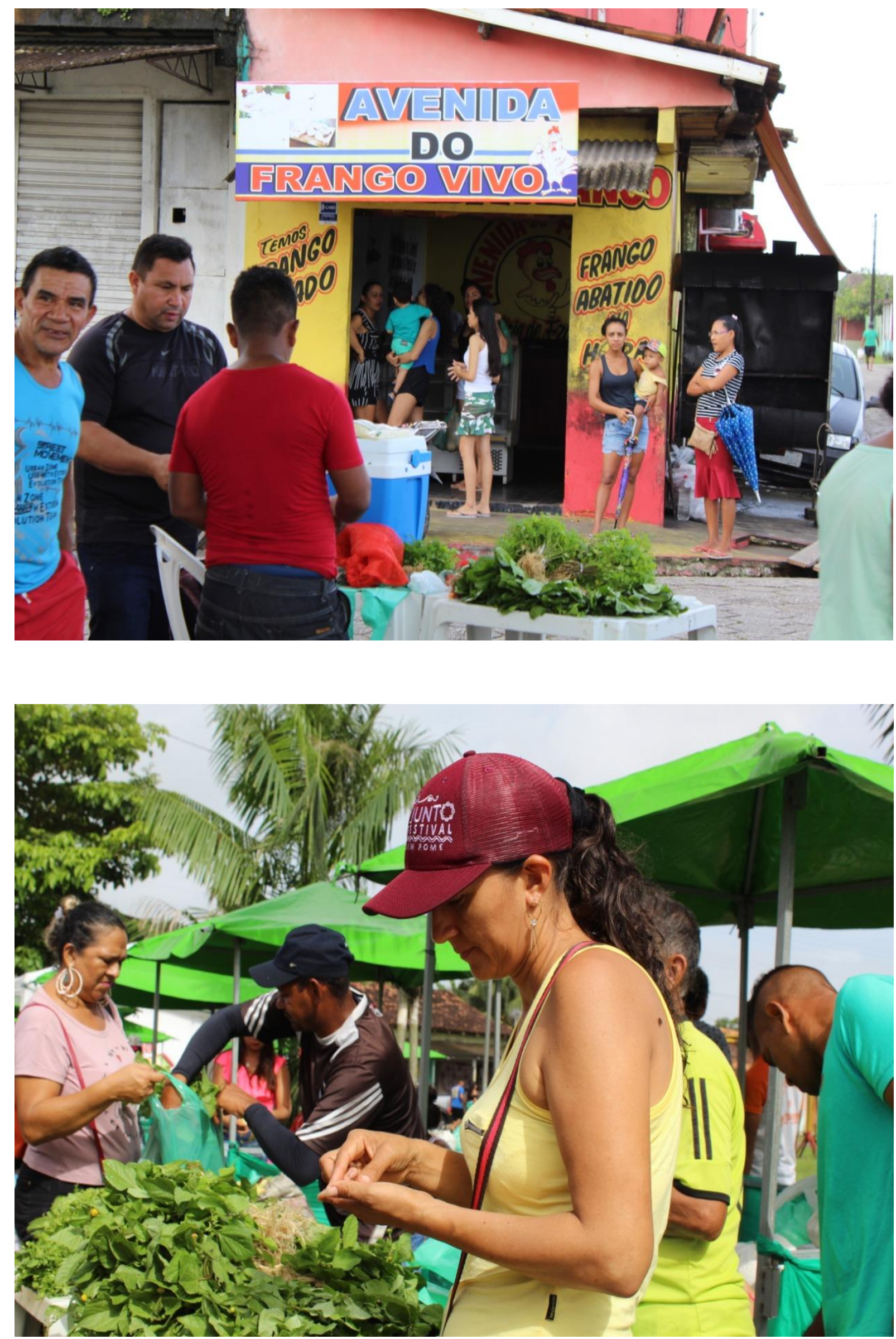

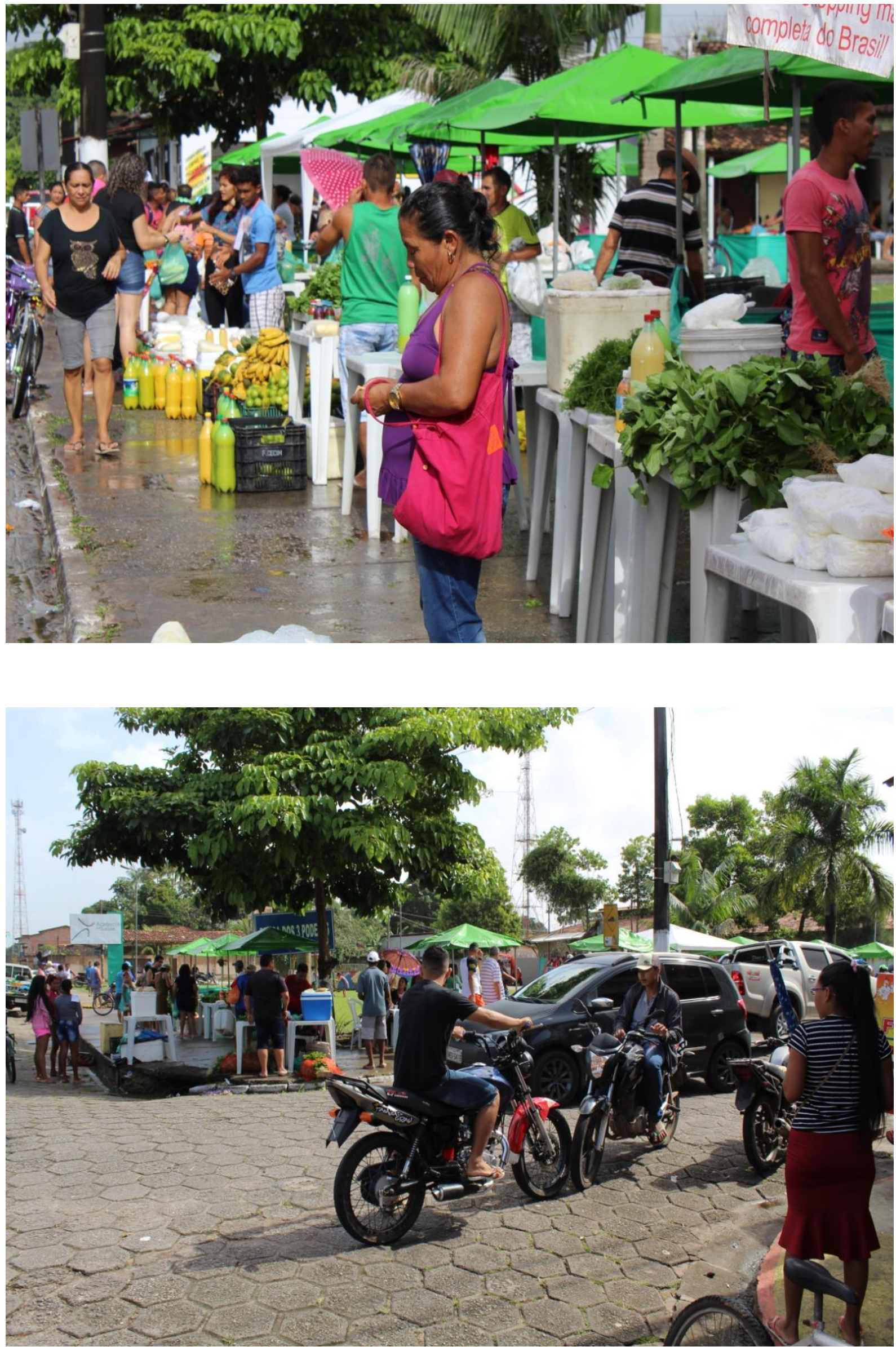

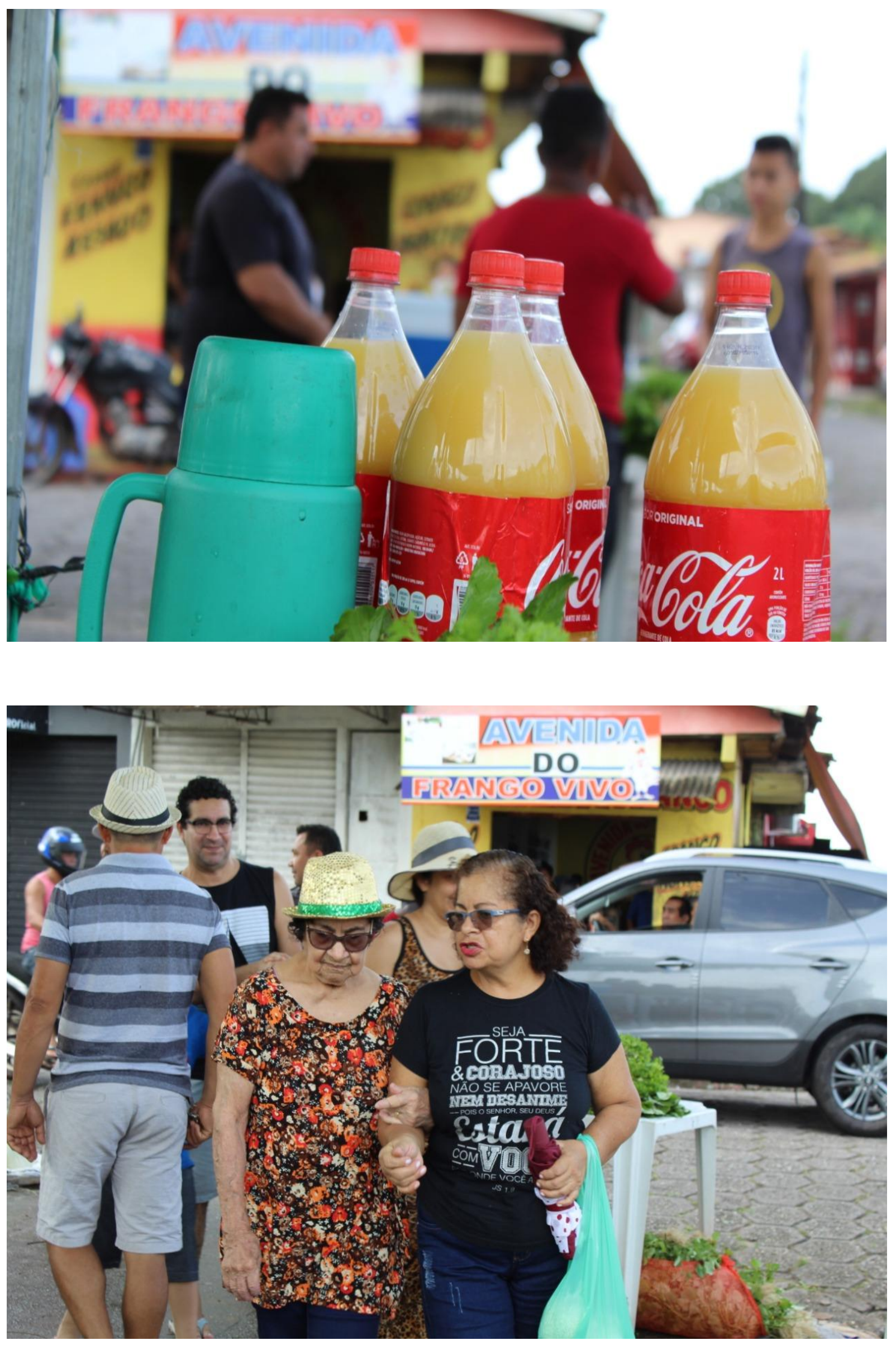